\title{
EFFECTIVENESS OF STRUCTURED TEACHING PROGRAMME ON KNOWLEDGE AMONG MOTHERS ON PRETERM CARE
}

\author{
*Mrs. S. Rajathi \& **Dr. R. Shankar Shanmugam
}

\section{INTRODUCTION:}

Preterm and low birth weight babies are at higher risk of death and severe morbidity than full term, not only during the neonatal period but also during infant and childhood. The chances of survival and well being of a new born begins well before birth and continue through the post partum period. Good care facilities, combined with the identification and appropriate management of newborn complications, are necessary to ensure optimal neonatal health outcomes. According to 2013 statistics, in India total live births- 1.22 billion, IMR-44.6 per 1000 live births and NMR-37per 1000 live births are reported.(www.who.com).The major medical causes of neonatal mortality are neonatal infections (33\%), birth asphyxia and trauma (28\%), preterm birth and low birth weight (24\%), congenital anomalies (10\%), and other causes (5\%). Birth Asphyxia, trauma, preterm and low birth weight are major contributors to morbidity in survivors.

\section{STATEMENT OF THE PROBLEM:}

A study to assess the effectiveness of structured teaching programme on knowledge among mothers on preterm care in Neonatology unit, Chennai-8

\section{OBJECTIVES OF THE STUDY:}

1. To assess the knowledge among mothers on preterm care.

2. To assess the knowledge among mothers on preterm care after the structured teaching program.
3. To evaluate the effectiveness of structured teaching programme on knowledge among mothers on preterm care.

4. To associate pre and post test knowledge score of mothers on preterm care with selected demographic variables.

\section{METHODOLOGY:}

The pre- experimental design, of one group pretest and post test design was adopted. Non randomized convenient sampling technique was used to select the samples of 60 mothers who were having preterm and low birth weight babies with an average weight of 1.5 to $2.5 \mathrm{~kg}$. The exclusion criteria includes preterm with congenital anomalies, sick and ventilator supported babies.

\section{DESCRIPTION OF THE INSTRUMENT:}

The structured interview questionnaire was prepared by the investigator based on the extensive review of literature, expert's opinion and investigator's personal experience. It consists of two sections. Section-1 : It deals with the demographic variables of the Subject. Section -2 : It consists of 40 multiple choice questions with 6 sub divisions. The scores given for preterm care are as follows, for correct answer-' 1 ' score and for wrong answer-' 0 ' score.

\section{DATA COLLECTION PROCEDURE:}

Permission was obtained from Neonatology Unit, Institute of Obstetrics and Gynaecology Chennai-8.After getting the informed consent, pretest was conducted and the same day investigator implemented structured 
teaching programme by using chart, hand outs and demonstration. At the end of the program fifteen minutes were allotted for discussion and return demonstration. After seven days, post test was conducted in the out patient department of well baby clinic.

\section{DATA ANALYSIS AND}

INTERPERTATION: The data were analyzed by using descriptive and inferential statistics and interpreted under the following sections,

Section-I : Demographic variables of mothers on preterm care.

Section-II : Distribution of mother's knowledge on specific aspects of preterm care before and after the structured teaching programme which was represented as pretest and post test scores.

Section-III : Shows effectiveness of structured teaching programme.

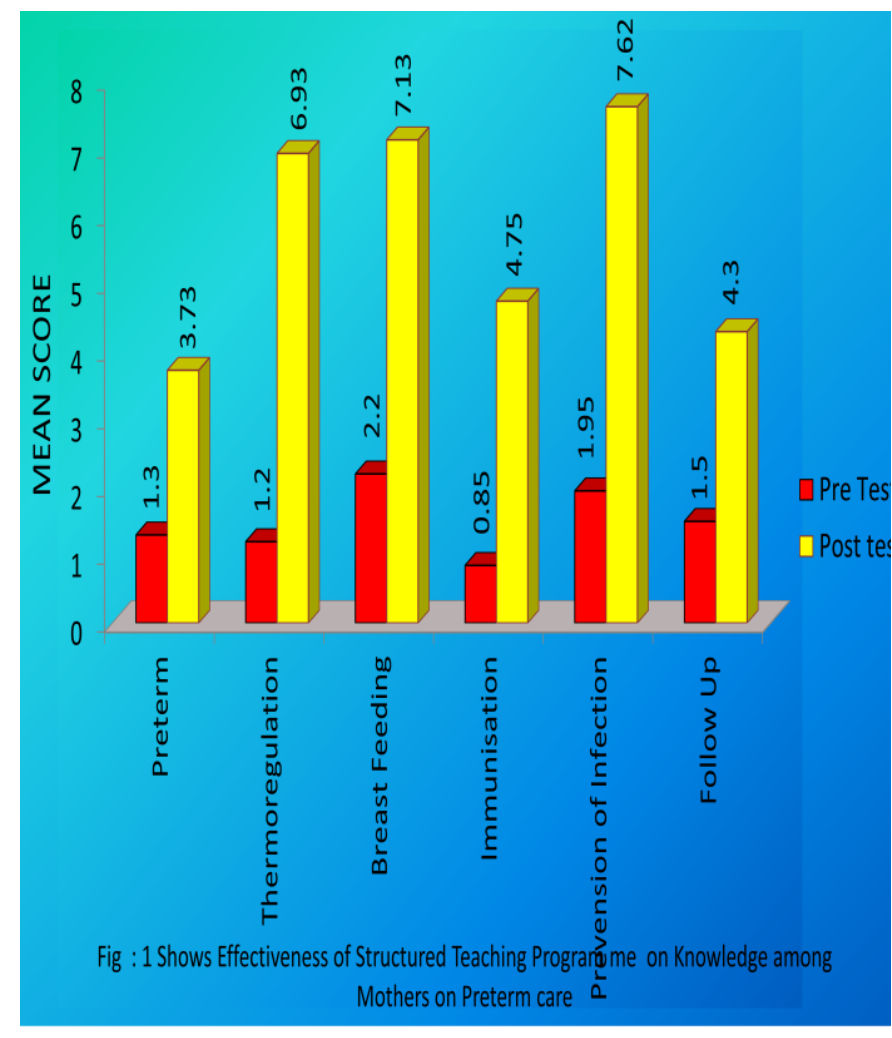

Section-IV : Association between demographic variables of mothers with the improvement score of overall knowledge on preterm care.

\section{MAJOR FINDINGS OF THE STUDY:}

In the pretest, none of the mothers had adequate knowledge (>60\%) around twelve per cent had moderate knowledge (40\%-60\%) and remaining eighty eight per cent had inadequate knowledge $(<40 \%)$ about the specific aspects of preterm care.

In the post test eighty seven per cent of the mothers had adequate knowledge $(>60 \%)$, remaining mothers had moderate knowledge (40\%-60\%)and none of the mothers have inadequate knowledge $(<40 \%)$ about the specific aspects of preterm care.

In this study, the paired ' $\mathrm{t}$ ' test value between the overall pretest and post test was 33.65 scores and, it shows the significance difference between the knowledge score in the pretest and post test.(P>0.05) .The effectiveness of structured teaching programme $(64 \%)$ is proved by the marked improvement of knowledge on specific aspects of preterm care.

There is a significant association between the overall improvement knowledge scores with demographic variables of mothers age, history of previous birth, mothers education, type of family and residence. In that, mother's age is more influence on knowledge of preterm care when compared with other significant demographic variables.

\section{CONCLUSION:}

Preterm and low birth weight infants are more likely to be hospitalized and require more acute care visits over the first year of life than infants born full term and at normal weight. The mother only the first person to satisfy the needs 
by protecting, comforting, and nurturing her child. "Structured teaching programme" has a great influence among mothers about their knowledge to take care of preterm babies which helps in reducing the morbidity and mortality rate and thus improving the quality of life.

\section{BIBLIOGRAPHY:}

Carole Kenner, Judy Weight Lott (1998), Comprehensive Neonatal Nursing. $3^{\text {rd }}$ ed, Soundars Company, Philadelphia.
Janet M.Rennie, (2000). Text book of neonatology. Churchill living stone, London.

Forslund M, Bjerre.I, (2005). Follow up of preterm children, Indian academic of pediatrics, Nov: 24: 107 -109.

Slusher T Hampton.R et al., (2003) Promoting care for hospitalized low birth weight and preterm infants. Paediatrics Today, May: 19(2)191-198. 